trainee look? I my case I was directed towards the Open Business School.

The Open Business School (OBS), part of the Open University, offers training in management techniques to nationally recognised standards. The Professional Certificate in Management is at MCI level and contributes towards national vocational qualification (NVQ) accreditation at level 4 (if competence in employment is shown). This can be extended to the Professional Diploma in Management (MCII level and NVQ level 5). The modules are studied at home with the textbooks, video and audio tapes provided. There is opportunity to meet fellow students from various industries with regular tutorials and a three day residential school.

Three assignments applying course principles to real work situations are submitted and count towards the final assessment, the other half from a written examination.

The Certificate in Managing Health Services (Cert MHS) is the introductory module for all those working in the health service (NHS Training Directorate, 1993) based on the OBS standard 'The Effective Manager'. It meets the needs of people moving into the operational level of management in the health service for the first time. I studied the course alongside other health care professionals all hoping to develop management skills, and it was a great leveller. Topics included managerial effectiveness and control, decision making, choosing, developing, leading and motivating the team, and organisational structures and cultures.

Completion of Cert MHS confers membership of the Institute of Health Service Managers (IHSM). If enthusiasm continues, further modules are studied for the diploma. I chose 'Managing People', 'Managing Change', 'Information Systems and Information Technology' and 'Managing in the Competitive Environment'.

I exposed my personal ignorances to others but this was a shared experience in a safe environment. I found management training has increased my confidence and increased my understanding in managing myself and the multidisciplinary team, an important skill for psychiatrists.

NHS TRAIning DIRECTORATE (1991) Management Development for Hospital Consultants. Bristol: NHS Training Directorate.

- (1993) MESOL: Management Education Scheme by Open Learning. Update 4. Bristol: NHS Training Directorate.

PEDLER, N., BURgoYNe, J. \& BOYDELL. T. (1978) A Manager's Guide to Self Development. London: McGraw-Hill.

KEVAN R. WYLIE, The General Infirmary at Leeds, Leeds LS1 3EX

\section{Clozapine withdrawal symptoms}

Sir: I read with interest the clozapine withdrawal symptoms described by Drs Palia and Clarke
(Psychiatric Bulletin, 17, 374-375) with subsequent correspondence by Dr Meltzer in (Psychiatric Bulletin 17, 626). In our 1974 paper on clozapine (Simpson \& Varga, 1974), we described patients who developed symptoms in the post drug-placebo period "which may have reflected a withdrawal effect." Symptoms lasted approximately one week and then remitted. In our 1978 publication (Simpson et al, 1978), three of seven patients treated "showed severe withdrawal effects within three to six days following clozapine discontinuation." They showed a marked clouding of consciousness, severe emotional withdrawal and muteness, with a quick return of their psychotic symptoms. Two of them were worse than during the baseline period. In all three, their tardive dyskinesia became worse even though this had improved during clozapine use.

We have seen these withdrawal or rebound phenomena on several occasions over the past few years. In uncontrolled studies, we have used anticholinergics to treat this since some of the symptoms appear similar to cholinergic rebound. We would, therefore, agree with Drs Palia, Clarke and Meltzer that clozapine should not be withdrawn abruptly unless absolutely necessary. If it is necessary, we would recommend the addition of anticholinergic medication and if a neuroleptic is needed, then a neuroleptic with anticholinergic properties such as chlorpromazine would be preferable to haloperidol.

SimpSON, G.M. \& VARGA, E. (1974) Clozapine - a new antipsychotic agent. Current Theory \& Research. 16, 679686.

- LeE, H.L. \& Shrivastava, R.K. (1978) Clozapine in tardive dyskinesia. Pharmacopharmacology. 56, 75-80.

George M. Simpson, Medical College of Pennsylvania, 3.200 Henry Avenue, Philadelphia, PA 19129, USA

\section{Television programmes and psychiatric treatment}

Sir: I was interested to read 'Situation comedy compliance' (Psychiatric Bulletin, 17, 625). The suggestion that popular television programmes should be used to inform the public of psychiatric treatments in a favourable light is especially important in view of the vast numbers of viewers of these programmes. 'Eastenders' and 'Casualty' can command audiences of 1015 million per episode, and can undoubtedly influence behaviour and attitudes.

With a long history of largely negative portrayal of the psychiatric profession in the media, the time has surely come for greater utilisation of this important resource by collaborating with scriptwriters and producers of such programmes to ensure that positive messages are received by 
the widest possible audiences, hopefully resulting in better compliance and understanding of psychiatric treatments.

SHAZAD AmIN, Queens Medical Centre, Nottingham NG7 2UH

\section{Community services for people with mental handicap}

Sir: I was interested to read Dora Kohen's paper 'Psychiatric Emergencies in People with Mental Handicap' (Psychiatric Bulletin 1993, 17, 587589). In a recent research project looking at patients discharged from institutions for the mentally handicapped I noticed gaps in community services. Maladaptive behaviours present prior to discharge are likely to persist in the community setting (Eyman et al, 1981) and problematic behaviours are worse immediately after moving into the community (Lowe et al, 1993). Also it is well known that epilepsy becomes more unstable during times of stress such as de-institutionalisation. On discharge such patients are usually separated from familiar staff who know how to deal with a certain patient's aggressive outbursts or can identify the prodromal phase leading upto an epileptic seizure. In view of all these factors, psychiatric emergencies are likely to increase immediately after discharge and there is no evidence to suggest drop to any great degree thereafter.

Many areas now have 'crisis teams' to deal with nine to five emergencies with mentally handicapped patients. Few of these extend to nights and weekends, leaving only GP and consultant cover. Also there are fewer acute psychiatric beds for the mentally handicapped than in the past and one would hope, in any case, that current services can offer a more imaginative action than a simple resort to admission for all emergencies. We must now be looking to consolidate and adapt community services to ensure easy access to the expertise previously confined to the institutions.

EYMAN, R.K., BORTHWICK, S.A. \& MLLER, C. (1981) Trends in maladaptive behaviour of mentally retarded persons placed in the community and institutional settings. American Journal of Mental Deficiency. 86, 437-447.

LOWE. K.. PAIVA. D.E. \& FELCE, D. (1993) Effects of a community-based service on adaptive and maladaptive behaviours: a longitudinal study. Journal of Intellectual Disability Research. 37, 3-22.

S. F. FOSTER, Registrar in Psychiatry, Mersey Regtonal Rotation, Greaves Hall Hospital, Banks, Southport PR9 8BP

\section{Allocation of registrar posts}

Sir: Tom McClintock (Psychiatric Bulletin 1993, 17. 563-564) highlights difficulties encountered in the allocation of registrar jobs in SW Thames which we in the Mid-Trent (Nottingham) rotation recognise. Since Achleving a Balance many training schemes have changed significantly (Davies \& Junaid, 1992) and posts included may now have a much greater geographical spread. Inclusion of peripheral posts should serve to expand opportunities to gain valuable experience.

In the Mid-Trent rotation the quality of peripheral posts is high and is monitored by the junior doctors themselves (Davies, 1993). Yet there is often reluctance by registrars to select posts away from Nottingham. The most commonly cited reason is the inconvenience of commuting to bases which may be over $\mathbf{4 0}$ miles away. A major attraction of entry to a rotational training scheme is the assurance of being employed in one geographical area for a number of years, encouraging house purchase or stable family arrangements. This effectively precludes many registrars 'living in' for six months at a peripheral post and necessitates daily travel. Around examinations times 'wasted' hours travelling may be strongly resented.

We have 13 registrar posts placed centrally (in Nottingham) and 13 peripherally (in Derby, Lincoln, Mansfield, Retford and Newark). Individuals might therefore expect to experience an equal number of peripheral and central posts.

One proposal to achieve an equitable distribution involves reducing the number of posts from which a selection can be made at any one time, by banding posts together into groups. Every six months an individual's preferences could be selected from one 'band' and the following six months he or she would select a post from the next band and so on. Final allocation of posts would be decided by committee. Suggested bandings are peripheral general/rehabilitation psychiatry posts, central speciality posts, peripheral speciality posts, and central general psychiatry posts.

Upon joining the rotation, entry into a particular band might be influenced by when trainees plan to sit part II of the membership examination, perhaps aiming to be in the fourth band at the time of their first attempt.

Clearly no allocation system is ideal. Avoidance of rigorous adherence to an over-prescriptive system is vital to permit flexibility for the continuously changing needs of an individual trainee and of the service in which he or she is employed.

DAVIES. S. (1993) Consumer audit of psychlatric training. Psychiatric Bulletin, 17, 503-504.

- \& JUnAid, I. (1992) Training for trainees. Psychiatric Bulletin, 16, 778-779.

M. MCCARTNEY, Thorneywood Child and Adolescent Psychiatry Unit, Nottingham NG3 6LF; and S. DAVIES Kings Mill Hospital, Sutton in Ashfield NG17 4HD 